\title{
Diet affects body color and energy metabolism in the Baikal endemic amphipod Eulimnogammarus cyaneus maintained in laboratory conditions
}

\author{
Alexandra Saranchina ${ }^{1}$, Polina Drozdova ${ }^{1,2}$, \\ Andrei Mutin ${ }^{1}$, and Maxim Timofeyev ${ }^{1,2}$ \\ 1'rkutsk State University, ul. Karla Marksa, 1, Irkutsk, 664003, Russian Federation \\ 2Baikal Research Centre, ul. Lenina, 21, Irkutsk, 664003, Russian Federation \\ Address correspondence and requests for materials to Maxim Timofeyev, \\ m.a.timofeyev@gmail.com
}

Citation: Saranchina, A., Drozdova, P., Mutin, A., and Timofeyev, M. 2021. Diet affects body color and energy metabolism in the Baikal endemic amphipod

Eulimnogammarus cyaneus maintained in laboratory conditions. Bio. Comm. 66(3): 245-255. https://doi.org/10.21638/ spbu03.2021.306

Authors' information: Alexandra Saranchina, Researcher, orcid.org/00000002-5756-1525; Polina Drozdova, PhD, Leading Researcher, orcid.org/0000-00033955-6105; Andrei Mutin, Junior Researcher, orcid.org/0000-0002-3092-5376; Maxim

Timofeyev, Dr. of Sci. in Biology, Professor, Director of Institute, orcid.org/0000-00025250-6818

Manuscript Editor: Kirill Antonets, Department of Cytology and Histology, Faculty of Biology, Saint Petersburg State University, Saint Petersburg, Russia

Received: January 9, 2021;

Revised: March 31, 2021;

Accepted: April 12, 2021.

Copyright: (c) 2021 Saranchina et al.

This is an open-access article distributed under the terms of the License Agreement with Saint Petersburg State University, which permits to the authors unrestricted distribution, and self-archiving free of charge.

Funding: This work was supported by the Russian Science Foundation (grant number 19-74-00045; animal sampling, experiments, carotenoid and protein measurements) and a joint project funded by the Russian Foundation for Basic Research and the Belarusian Republican Foundation for Fundamental Research (grant numbers 19-54-04008 and B19RM-097, respectively; glucose and glycogen measurements).

Ethics statement: The studied species are highly abundant and not endangered or protected. All applicable international, national, and institutional guidelines for the care and use of animals were followed. The research was approved by the Animal Subjects Research Committe of the Institute of Biology at Irkutsk State University (ASRC Protocol No 2018-3).

\begin{abstract}
Proper diet is critical for laboratory-reared animals, as it may affect not only their welfare, but also experimental results. Amphipods (Crustacea: Amphipoda) play important roles in ecosystems and are often used in environmental research. Endemic amphipods from the ancient Lake Baikal are promising for laboratory bioassays; however, there are currently no laboratory cultures. In this work, we determine how different diets affect the color and metabolism of a laboratory-reared Baikal amphipod, Eulimnogammarus cyaneus. We found that in freshly collected blue-colored animals, body color correlated with total carotenoid content. Total carotenoid levels did not differ after long-term (two months) feeding with a close to natural carotenoid-enriched, or even a carotenoid-depleted diet. Nevertheless, antennae color was closer to red in the natural-like diet group. It is likely that the carotenoids from the commercial diet are not properly metabolized in E. cyaneus. The animals fed commercial diets had a higher glycogen content, which may signify a higher metabolic rate. Overall, we show that a carotenoid-enriched diet optimized for decapods is not optimal for amphipods, likely due to different carotenoid compositions, and the diet for long-term rearing of E. cyaneus and other Baikal amphipods requires supplementation.
\end{abstract}

Keywords: carotenoids, diet, laboratory rearing, Baikal, Amphipoda, Crustacea, Decapoda, culture, metabolites

\section{Introduction}

The order Amphipoda (Crustacea: Malacostraca) includes about 10,000 discovered species (Arfianti et al., 2018), and this number is likely higher once cryptic diversity within morphological species is taken into account (Wattier et al., 2020). Amphipods occupy extremely diverse ecological niches from deep aquatic environments to saltwater, brackish water and freshwater, lentic and lotic, and cave and semi-terrestrial habitats (Spicer et al., 1987; Villacorta et al., 2008; Fišer et al., 2017; Brix et al., 2018). They include benthic, pelagic, and benthopelagic species, as well as some semi-terrestrial and substrate (e.g., driftwood) specialists (Wildish et al., 2012; Xavier et al., 2020). Due to the wide distribution of amphipods and their important roles in ecosystems, amphipod-based bioindication, environmental monitoring, and biotoxicity assessment systems are actively under development (e.g., Hyne et al., 2005; Alonso et al., 2010; Podlesińska and Dąbrowska, 2019; Du et al., 2020). Due to their high biomass and wide distribution, amphipods play essential roles in many food webs and are considered aquaculture prey (Baeza-Rojano et al., 2009; Woods, 2009; Vargaz-Abundez, 2021). For some amphipod species (Parhyale hawaiensis, Hyalella azteca, and Gammarus pulex), permanent laboratory cultures are well established to facilitate ecotoxicology studies 
(McCahon and Pascoe, 1988; Pascoe et al., 2001; Artal et al., 2018).

Lake Baikal, one of the deepest and oldest lakes on Earth, is a center of extreme amphipod diversity (Väinölä et al., 2008). Over 350 species and subspecies of amphipods are endemic to the lake (Takhteev, 2019) and are being actively investigated in multiple ecological and evolutionary studies (Macdonald et al., 2005; Bedulina et al., 2013; Naumenko et al., 2017; Bedulina et al., 2020). Laboratory cultures would afford significant advantages; however, permanent cultures of Baikal amphipods have yet to be established.

In laboratory cultivation, as well as in any maintenance of laboratory animals, diet is an extremely important parameter that affects metabolism and can therefore influence the results of the study. Indeed, peroxidase activity significantly increased in laboratory-reared E.cyaneus over time when fed commercial fish food TetraMin (Timofeyev et al., 2009). We investigated how different diets influence some biochemical parameters of several amphipod species, including Eulimnogammarus cyaneus, a relatively small fast-developing species and a promising candidate for laboratory culture. Recently, a comparison of a commercial crustacean diet (Tetra Crustaceans Menu, TCM), vegetable mix (potatoes and carrots), Baikal feed mixture (dried and ground mix of amphipods (mostly Eulimnogammarus sp.), and macrophytes (mostly Elodea canadensis) from Lake Baikal littoral, BFM) was performed with a focus on oxidative stress markers, weight, and total protein content (Axenov-Gribanov et al., 2019). While all chosen diets allowed maintenance of weight and protein content over 12 weeks, feeding with TCM and BFM was associated with a gradual decrease in the glutathione S-transferase and lactate dehydrogenase activities.

The levels of metabolites, such as glucose and glycogen, are also diet-regulated. Different crustacean species exploit different strategies of glycogen usage when food is scarce. For example, after 180-day starvation, glycogen levels decreased nearly two-fold in cave amphipods, Niphargus rhenorhodanensis and N. virei, but after refeeding, animals actively replenished their glycogen stocks (Hervant et al., 1999). At the same time, the level of glycogen levels in G. fossarum decreased over four times after only a 28-day starvation, and the level of glucose also decreased (Hervant et al., 1999; Semsarkazerouni et al., 2020). Baikal amphipods have also been shown to use glycogen stocks when under stress; for example, Gmelinoides fasciatus decreases glycogen levels in response to increases in temperature (Lubyaga et al., 2020). Thus, the quantity and quality of the diet will affect glycogen and glucose levels, which means not only that these metabolites can be used as a proxy to assess the metabolic condition, but also that their contents can influence the response to environmental factors.
Another important and unusual characteristic of Baikal amphipods is great variability in coloration, not only between species, but also within a species. The coloration of crustaceans depends mainly on carotenoid pigments. Crustaceans are not capable of synthesizing carotenoid pigments de novo, even though they can perform some biotransformation reactions. Thus, they rely on carotenoids from their diet (plant, fungi, algae, or bacteria; Maoka, 2020). The most common carotenoid in decapod crustaceans is astaxanthin, which may exist both in free form or bound to the crustacyanin protein (Maoka, 2011). Free carotenoids are red, orange, or yellow, whereas carotenoid-protein complexes can be orange or yellow as well as blue or violet (Chayen et al., 2003; Maoka, 2020).

Representatives of the genus Gammarus may change their body color due to infection with acanthocephalan parasites (Gaillard et al., 2004). The coloration of deep-water amphipod species Eurythenes gryllus and Anonyx sp. possibly depends on carotenoid composition, which is a consequence of their diets (Thoen et al., 2011). However, body color of cave amphipods from the genus Niphargus is determined by light intensity and not the carotenoid content of their diet (Beatty, 1949). Thus, body color is a result of the interplay of many mechanisms, including diet composition.

The direct influence of dietary carotenoids on coloration is best studied in decapod crabs and shrimp (Wade et al., 2017). For example, young lobsters (Homarus americanus) fed a low-astaxanthin diet became blue, while those fed a high-astaxanthin diet became red (Tlusty and Hyland, 2005). Similarly, cooked Marsupenaeus japonicus shrimp are typically light pink, but can be red if they were fed an astaxanthin-supplemented diet (Wang et al., 2018). However, there have been no similar studies for amphipods, even though the effect of carotenoid-rich and carotenoid-poor diets on fatty acid composition and on level of carotenoids in the hemolymph has been studied in a marine amphipod G. locusta (Alberts-Hubatsch et al., 2019) and in freshwater G. fossarum (Babin et al., 2020), respectively.

Eulimnogammarus cyaneus can be found in a continuous range of colors from bright blue through bluish green to bright orange (Kamaltynov, 2001; Drozdova et al., 2020), suggesting that both genetic and environmental variables contribute to coloration. Investigation of the role of carotenoids and carotenoid-protein complexes in coloration of the common blue and rare orange morphs of E.cyaneus indicates that higher amounts of carotenoid-binding proteins, analogous to crustacyanins, generate the blue morph, despite similar total carotenoid content to the orange morph (Drozdova et al., 2020). However, the extent to which the color may change throughout the life of a particular individual and the role of dietary carotenoids in these color changes remains unclear. 

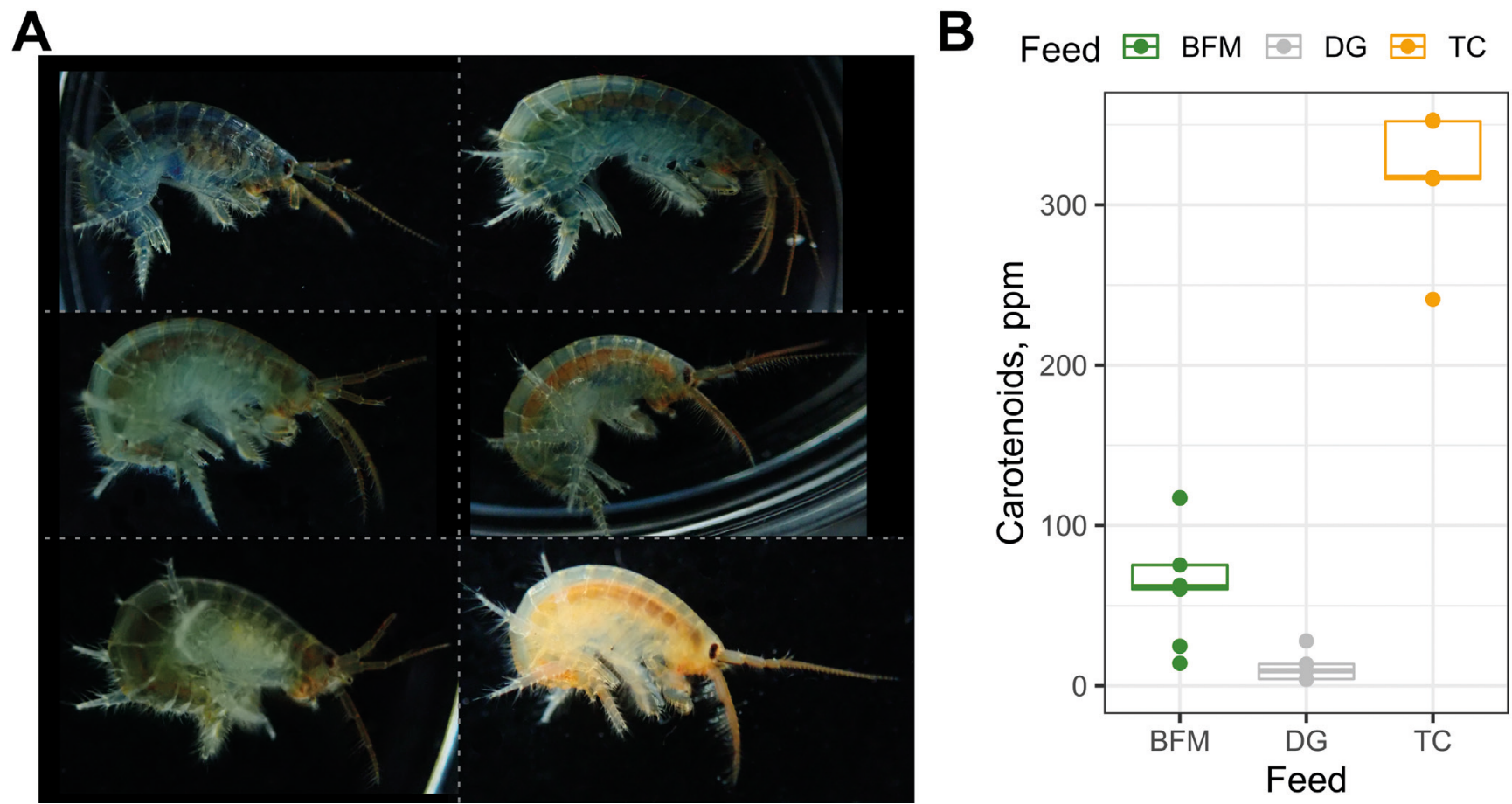

Fig. 1. (A) Examples of different colors of E. cyaneus (from bright blue in the upper left to fully orange in the lower right). (B) Carotenoid content of different diets: Baikal feed mixture (BFM), dried Gammarus (DG), and TetraCrusta (TC).

In this work, we aimed to identify critical dietary factors for laboratory rearing of Baikal amphipods using the abundant littoral species E. cyaneus. In particular, we explored if and how different diets impact metabolism and the species' characteristic blue color.

\section{Materials and methods}

\section{Study species}

Eulimnogammarus cyaneus (Dybowsky, 1874) is an abundant littoral species widely considered representative of Baikal littoral amphipods (e.g., Jakob et al., 2017; Bedulina et al., 2020). The majority of individuals (90\%) are found at the shoreline (up to $1 \mathrm{~m}$ in depth) (Kamaltynov, 2001). Adult individuals can grow to 10$15 \mathrm{~mm}$ in length and breed in the summer. Their lifespan is 3-5 years, similar to most other littoral Eulimnogammarus species (Bedulina et al., 2014). Originally this species was considered detritivorous based on gut contents (Cyanobacteria, diatom and green algae, Chironomidae larvae, and detritus) (Morino et al., 2000); however, more recently, crustaceans, ciliates, and Oligochaeta chaetae were also found in the gut (Mekhanikova, 2015). While the body color was first characterized as greyish blue (Dybowsky, 1874), later the variability of body colors was described as a continuous palette from sky blue to completely orange, with the dominant morph being greenish-blue with orange antennae (Kamaltynov, 2001) (Fig. 1A).

\section{Sampling and experiments}

We monitored body color long-term during laboratory rearing; studied the factors that contribute to freshly collected animal body color; and quantified the effects of different diets on body color and metabolism. We collected adult males and non-gravid females, approximately $10-15 \mathrm{~mm}$ in length, using a hand net at $0-1 \mathrm{~m}$. All animals were transported to the laboratory in insulated plastic boxes and acclimated at $+6-8^{\circ} \mathrm{C}$. During acclimation, animals were fed twice weekly Baikal feed mixture (BFM), which consisted of Baikal littoral amphipods, algae, and macrophytes that were first frozen, then dried at low heat (up to $40^{\circ} \mathrm{C}$ ), and finally ground into a homogeneous powder (Jakob et al., 2017). The amphipods were then housed in continuously aerated 2-L plastic tanks with Baikal water and 2-3 sterile stones per tank. Water changes were performed biweekly.

Animals used for long-term body color monitoring were collected in June 2020 from the Listvyanka settlement (South Baikal; 51 $\left.52^{\prime} 14.07^{\prime \prime} \mathrm{N} 104^{\circ} 49^{\prime} 41.78^{\prime \prime} \mathrm{E}\right)$ (Fig. S1) ${ }^{1}$. The animals used to investigate the factors that contribute to body color were collected in August 2020 from the Bolshie Koty settlement (South Baikal; 51 $54^{\prime} 11.67^{\prime \prime} \mathrm{N}$ $105^{\circ} 4^{\prime} 7.61^{\prime \prime} \mathrm{E}$ ) (Fig. S1). The median weight of the animals sampled in Bolshie Koty was $22 \mathrm{mg}$ (range 13-40 mg). These two locations are approximately $20 \mathrm{~km}$ apart, with

1 Supplemental material to the article is available at https://biocomm.spbu.ru/article/view/10114 
no apparent physical barriers separating the E.cyaneus populations, and the population data indicates this species is highly genetically homogeneous (Gurkov et al., 2019).

To explore the effect of food composition on body color and metabolism, animals were collected twice near Listvyanka, first in July 2019 and again in January 2020, to correlate with seasons of high and low food availability, respectively (Fietz et al., 2005; Belykh et al., 2006). The summer cohort was acclimated for 11 days and then divided into two groups (51 individuals per group); one group continued with BFM, while the second group was changed to a commercial diet high in carotenoids, Tetra Crusta (TC) (Germany). Both groups were fed ad libitum (the amount of food per individual was not quantified) twice a week for a total of 61 days.

The winter cohort was acclimated for a week and then divided into three groups (39 individuals per group) and fed BFM, TC, or a ground dried commercial fish food, large Gammarus (DG) (Barnaul, Russia), respectively, twice a week for 52 days. In this case, the amount of food was calculated as $2.5 \mathrm{mg}$ per individual per day, the maximum amount at which food leftovers were not observed.

For both cohorts, the same lot of food was used throughout the entire experiment, and water temperature was maintained at $6-10^{\circ} \mathrm{C}$. After approximately two months, all surviving animals were anesthetized with clove oil ( $1: 10^{5}$ dilution in water), photographed, and then flash-frozen in liquid nitrogen. The median weight of the animals was quantified at the end of the experiment and was equal to $27 \mathrm{mg}$ (range 13-60 mg) in the summer cohort and $20 \mathrm{mg}$ (range 9-45 mg) in the winter cohort.

\section{Taking photographs and determination of body color}

All photographs were taken using an Olympus Tough TG-5 camera. Animals were photographed in front of a black background in summer, and a grey background in winter. The color index of pereon (approximately $6^{\text {th }}$ segment) and antennae was calculated from color corrected photographs as the ratio of intensities in the red and blue channels extracted with GIMP v.2.8, as described earlier (Drozdova et al., 2020).

\section{Measurement of carotenoid content}

Total carotenoids were extracted from animals by first homogenizing the tissues in acetone followed by petroleum ether for subsequent extraction. The total carotenoid content was then measured using a Cary 50 Conc UV/visible spectrophotometer (Varian) at $450 \mathrm{~nm}$ (Drozdova et al., 2020).

\section{Protein electrophoresis}

Quantification of crustacyanin analogs was performed using one-dimensional sodium dodecyl sulfate-polyacrylamide gel electrophoresis (1D-SDS-PAGE) with animal hemolymph. The relative abundance of each band of interest was determined by densitometry of scanned gels stained with Coomassie G250 (Drozdova et al., 2020) and ImageJ/Fiji software (Schindelin et al., 2012; Schneider, 2012).

\section{Measurement of glucose and glycogen content}

Glucose and glycogen content was determined according to the published method (Vereshchagina et al., 2016) with modifications as follows. Samples (pools of three animals) were ground into a powder, mixed with $0.6 \mathrm{M}$ $\mathrm{HClO}_{4} / 150 \mathrm{mM}$ sodium ethylenediaminetetraacetate $(1.5 \mathrm{ml}$ per $100 \mathrm{mg}$ wet weight), and homogenized in a Potter-Elvehjem tissue grinder until no visible particles remained. Next, $12 \mu \mathrm{l}$ of homogenate was used to measure glycogen content by mixing it with $75 \mu \mathrm{l}$ of $1 \%$ amyloglucosidase (Sigma; $5250 \mathrm{U} / \mu \mathrm{l}$ ) in a $0.2 \mathrm{M}$ acetic acid buffer (acetic acid/sodium acetate; $\mathrm{pH}$ 4.8). The mix was incubated at $40^{\circ} \mathrm{C}$ for two hours with shaking and then $62.5 \mu \mathrm{l}$ of $0.6 \mathrm{M} \mathrm{HClO}_{4}$ and $400 \mu \mathrm{l}$ of $1 \mathrm{M} \mathrm{KHCO}_{3}$ was added. The supernatant was centrifuged at $16060 \mathrm{RCF}$ for 10 minutes. The remaining homogenate was centrifuged at $15570 \mathrm{RCF}$ for 15 minutes and neutralized with $5 \mathrm{M} \mathrm{K}_{2} \mathrm{CO}_{3}$ until it reached a $7.5 \mathrm{pH}$. Next the neutralized homogenate was incubated at $+4^{\circ} \mathrm{C}$ for one hour. Then it was centrifuged at $15570 \mathrm{RCF}$ for another 15 minutes.

Glucose and glycogen concentration were measured in a reaction mixture containing $300 \mathrm{mM}$ TEA (triethanolamine), $91 \mathrm{mM}$ ATP, and $6 \mathrm{mM} \mathrm{NADP}$ at $37^{\circ} \mathrm{C}$. For the measurement (one hour), a $200 \mu \mathrm{l}$ sample and $0.7 \mu \mathrm{l}$ of glucose-6-phosphate-dehydrogenase $(30,681 \mathrm{U} / \mu \mathrm{l}$, Roche) that was diluted in $5.6 \mu \mathrm{l}$ of $3.2 \mathrm{M}\left(\mathrm{NH}_{4}\right)_{2} \mathrm{SO}_{4}$ and $1 \mu \mathrm{l}$ of hexokinase ( $150 \mathrm{U} / \mu \mathrm{l}$; Roche) was diluted in $5 \mu \mathrm{l}$ of $3.2 \mathrm{M}\left(\mathrm{NH}_{4}\right)_{2} \mathrm{SO}_{4}$. Light absorption was measured at $340 \mathrm{~nm}$ with a Cary 50 Conc UV/visible spectrophotometer (Varian).

\section{Data analysis}

Data analysis was performed in the $\mathrm{R}$ programming environment ( $\mathrm{R}$ Core Team, 2019) v3.6.1. The plots were visualized with the ggplot2 package (Wickham, 2016) v3.2.1 for R. Groups of samples were compared using a Mann - Whitney rank-sum test and Holm correction for multiple comparisons if necessary. The code used for data analysis is available from GitHub (https://git.io/JLhTo).

\section{Results}

\section{Color changes may occur throughout life}

According to our previous experience (Drozdova et al., 2020), we chose the pereon and antennae (Fig. 2A) as body parts that most accurately described the color of an individual. We chose 16 freshly collected animals of 


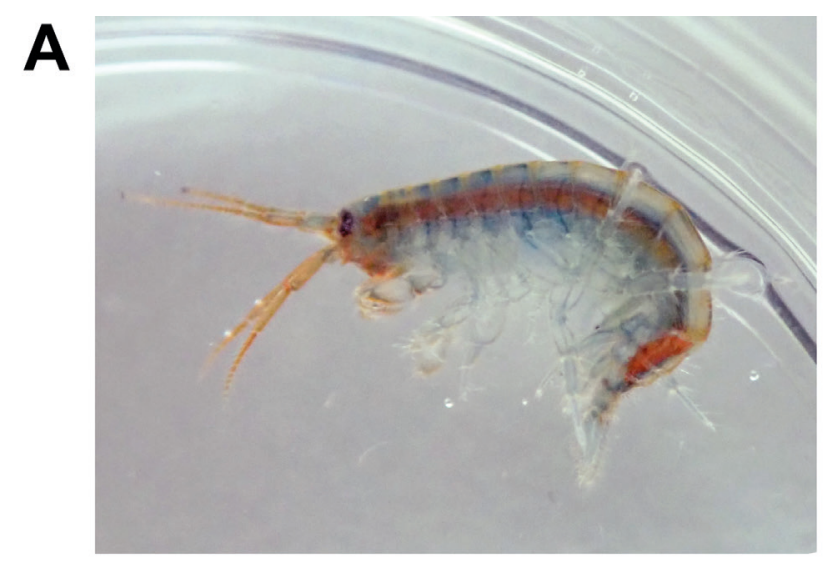

\section{B Pereon color}

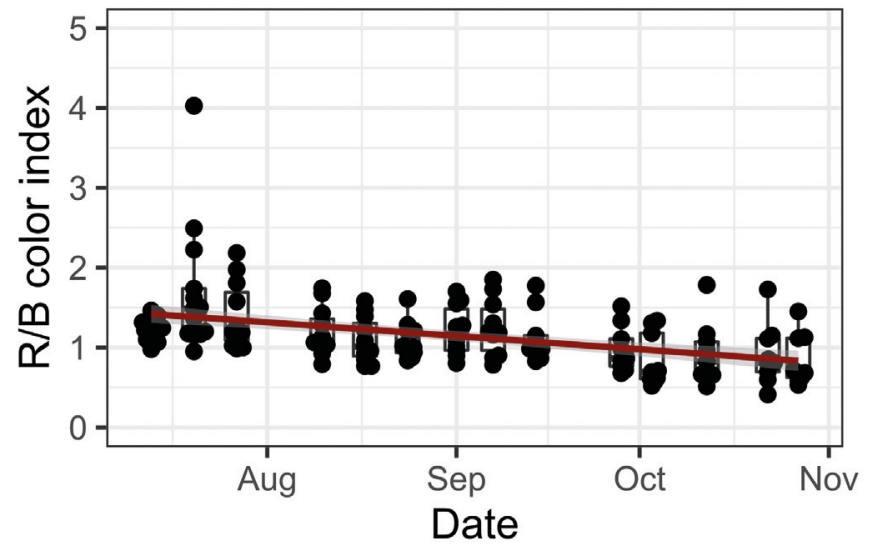

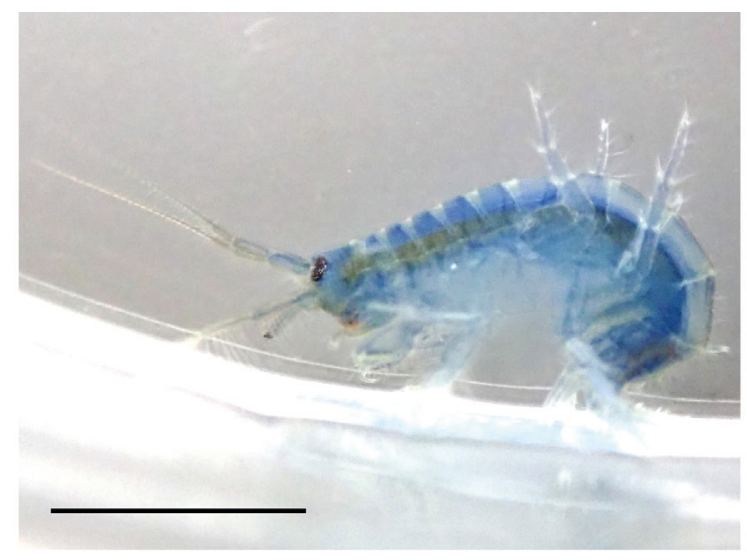

C Antennae color

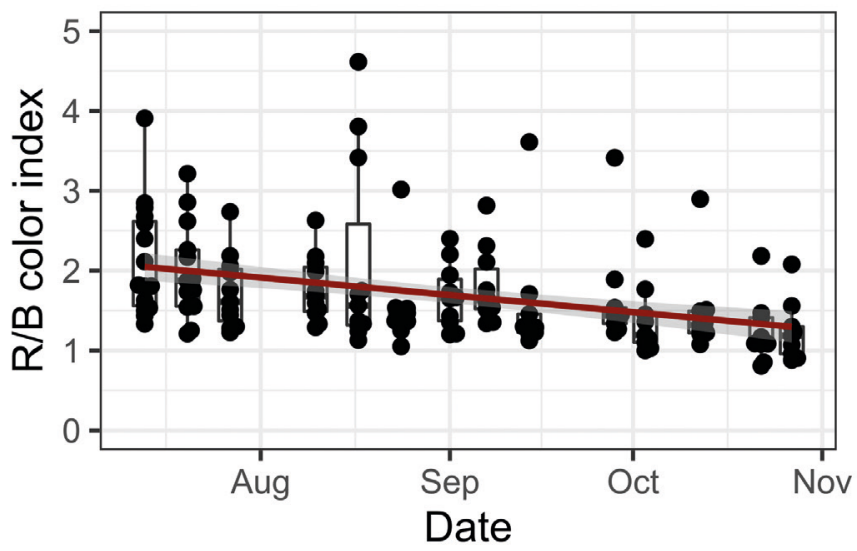

Fig. 2. The color of pereon and antennae gradually shifts towards blue during long-term rearing in laboratory conditions (BFM diet). (A) Example photos of animals in the beginning of the experiment (left) and over four months (right). The brightness and contrast were slightly adjusted for easier comparison. The scale bar is approximately $5 \mathrm{~mm}$. (B) Changes in pereon color index. (C) Changes in antennae color index. The red line depicts the linear regression.

different colors (from blue to orange), determined the color indices of their pereon and antennae, and fed them BFM (2.5 mg per individual per day) for approximately 18 weeks; nine animals survived until the end of the observation. We found that color indices of both pereon and antennae gradually shifted towards blue over the 18 week period (Fig. 2B, C).

\section{In blue animals, the color index correlates with carotenoid content but not protein content}

To get an idea if carotenoids may be connected to color in E.cyaneus, we explored the natural variation of the typical blue color morph. We chose 18 animals characterized by slightly different body colors, as well as 6 orange animals, from the same sample and photographed them to obtain a quantitative estimate of their body color (Fig. S2), then extracted their hemolymph. The hemolymph was used to assess the level of $15-\mathrm{kDa}$ and $25-\mathrm{kDa}$ crustacyanin analogs (Fig. 3B, C), while the remaining tissues were used to assess carotenoid content (Fig. 3A) (Drozdova. et al., 2020).
We found a subtle but statistically significant $(\mathrm{p}=$ 0.044) positive linear relationship between the color index and the total carotenoid content, but not crustacyanin analogs. Given this relationship, and the fact that E. cyaneus obtains carotenoids from food, we decided to experimentally manipulate dietary carotenoid levels to see if it would affect animal body color.

\section{Diet affects color index of antennae but not carotenoid content}

To explore the effect of food composition on the color and metabolism of E.cyaneus, we varied the diet of adult animals in both summer and winter, seasons of high and low food availability, respectively (Fietz et al., 2005; Belykh et al., 2006). The baseline diet, BFM, consisted of material from Lake Baikal littoral zone and the presumed natural diet of littoral amphipods. Treatment groups were fed a carotenoid-enriched commercial diet for shrimp and crabs (TC) or commercially available dried Gammarus sp. (DG). The carotenoid content in BFM widely varied depending on the particular batch, with a median value 


\section{A Carotenoids}

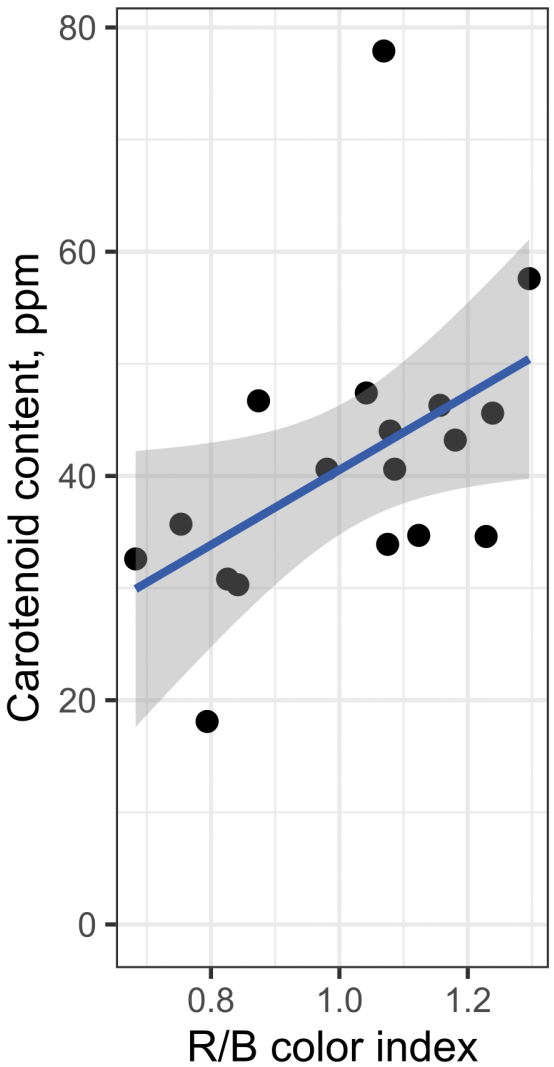

B $15 \mathrm{kDa}$ protein

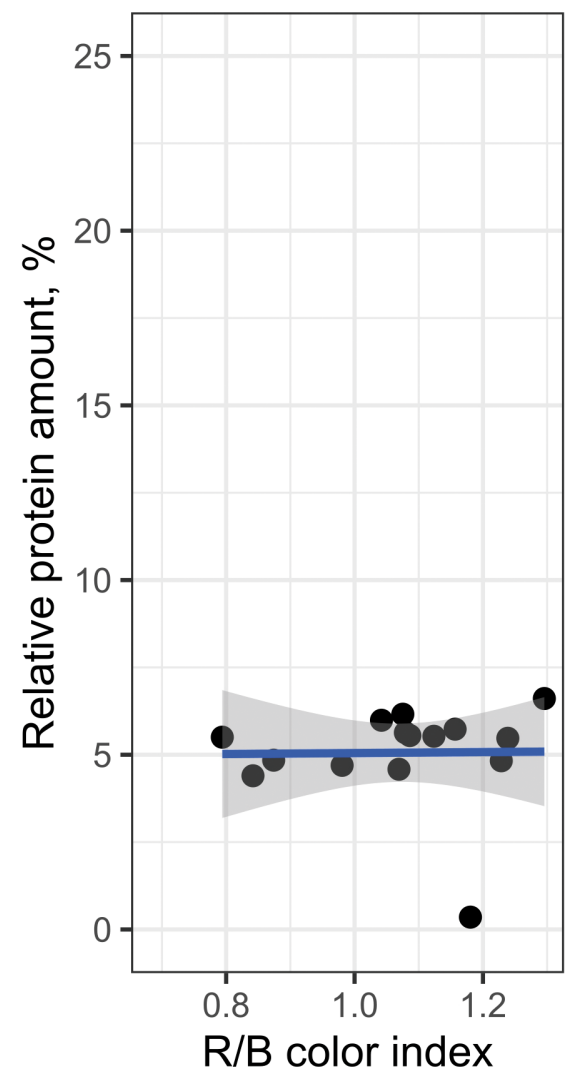

C $25 \mathrm{kDa}$ protein

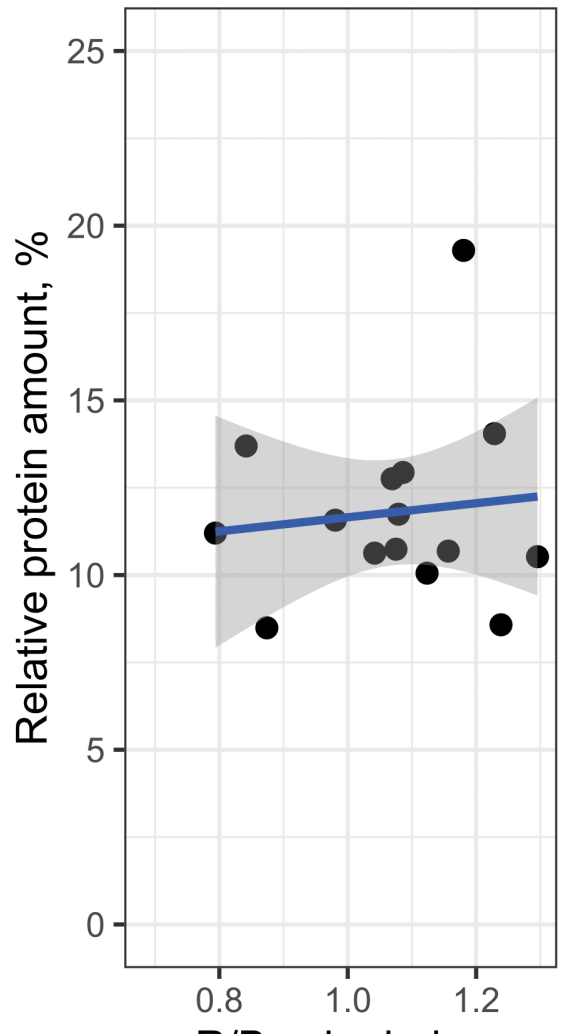

$\mathrm{R} / \mathrm{B}$ color index

Fig. 3. Color index in blue-colored animals from a natural population correlates with carotenoid content. Shown is the relationship between pereon color and carotenoid (A) or crustacyanin analog protein $(B, C)$ content in a natural population of $E$. cyaneus. Each dot represents an individual animal. The blue lines and gray shades are automatically fitted linear regressions and their confidence intervals, respectively.

of $62 \mathrm{ppm}$. The carotenoid content of TC was about five times higher (median $=317 \mathrm{ppm}$ ), while the amount of carotenoids in DG was only 11 ppm (Fig. 1B).

Survival was relatively low and seemed to differ between diets in the summer $(84.3 \%$ for BFM vs. $58.8 \%$ for TC), while it was much higher and more consistent across diets in winter $(92 \%, 97 \%$, and $90 \%$ for BFM, DG, and TC, respectively) (Fig. S3). Since this was only observed during summer, it is unlikely a result of the diets and is more likely explained by an unaccounted difference in the rearing conditions. According to our data, the wet weight of the animals was not significantly different (Fig. S4), nor did we notice any clear difference in feeding behavior when fed BFM versus TC or DG.

After the experiment, we photographed all animals individually to quantify body color. We found that in both seasons, antennae color in the group fed BFM was redder than in the animals fed carotenoid-depleted DG and, surprisingly, also carotenoid-rich TC (Fig. 4C, D). Unexpectedly, in both seasons, all groups had approximately the same total carotenoid content. However, the median carotenoid content in animals collected in the summer was approximately $10 \mathrm{ppm}$ higher than those collected in winter (Fig. 5A, B).

\section{Diet affects energy metabolites}

To understand how the different diets impacted amphipod metabolism, we also measured glucose and glycogen content. The level of glycogen showed profound diet-related differences (Fig. 5C, D). Animals fed BFM had the lowest glycogen content (median values of 1.5 and $3.0 \mu \mathrm{mol} / \mathrm{g}$ wet weight in summer and winter, respectively), followed by DG $(3.79 \mu \mathrm{mol} / \mathrm{g})$, and finally TC, with the highest amount of glycogen (5.6 and $6.3 \mu \mathrm{mol} / \mathrm{g}$ ). Glucose level was not significantly different between TC and BFM (between 0.8 and $1.1 \mu \mathrm{mol} / \mathrm{g}$ wet weight in summer and winter), but it was lower in the DG group $(0.45 \mu \mathrm{mol} / \mathrm{g})$ (Fig. 5E, F).

\section{Discussion}

Amphipods, including endemic amphipods of Lake Baikal, are widely used in environmental monitoring and biotoxicity assessments (e.g., Podlesińska and Dąbrowska, 2019; Du et al., 2020). However, there is no standard protocol for laboratory rearing of Baikal amphipods. In this work, we aimed to identify some of the key dietary factors for laboratory rearing of Baikal am- 


\section{A Pereon color}

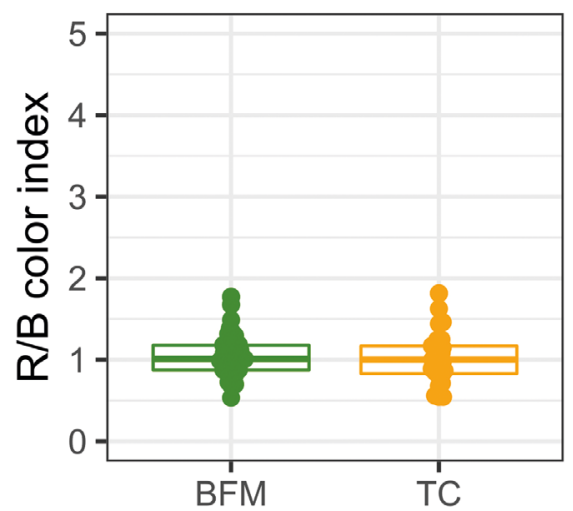

Feed

\section{Antennae color}

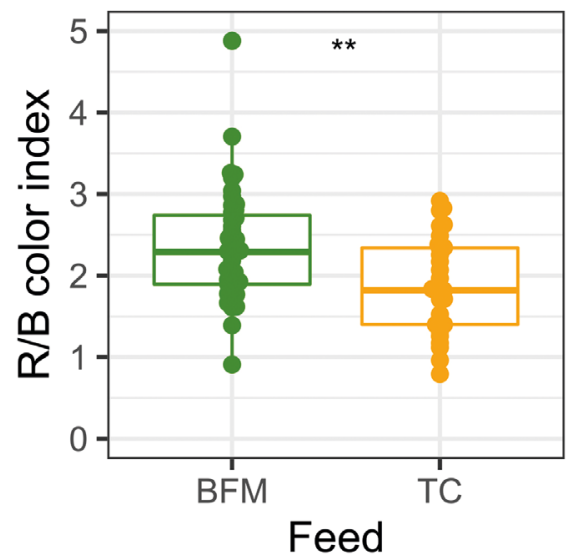

B Pereon color

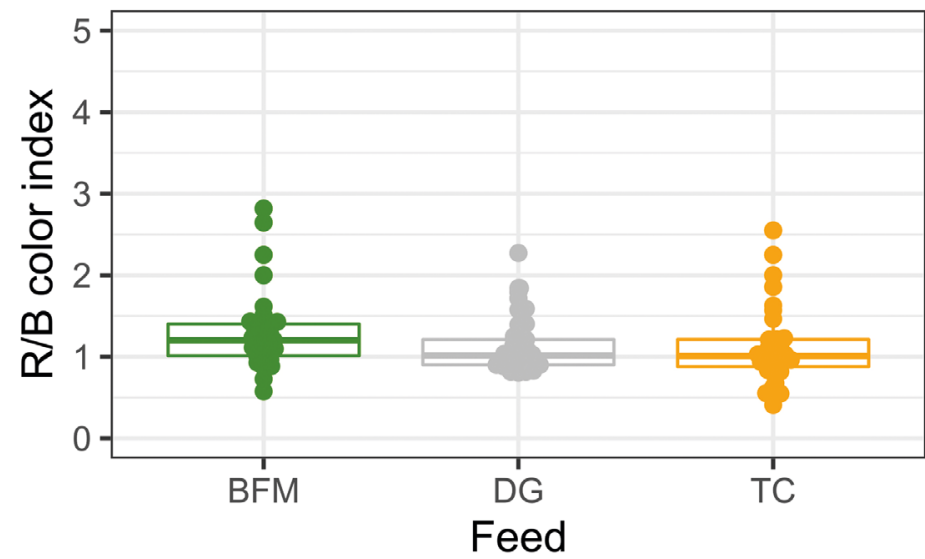

D Antennae color

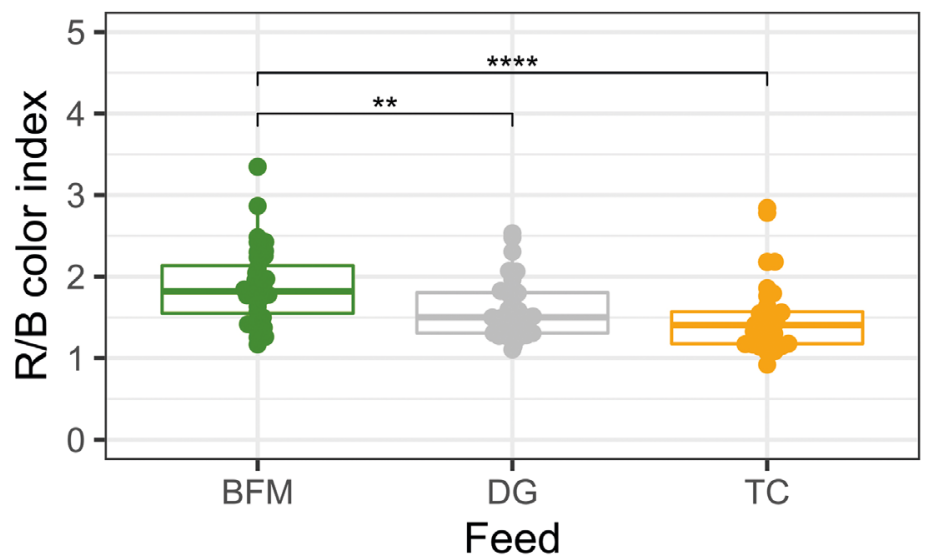

Feed

BFM

DG

TC

Fig. 4. The pereon color index is similar in animals fed different diets, while antennae color varied. (A) and (C) show the results of the first feeding experiment (summer cohort), while (B) and (D) show the results of the second experiment (winter cohort).

${ }^{*} p<0.05 ;{ }^{* *} p<0.01 ; * \star * p<0.001$ (Mann-Whitney rank sum test with Holm's correction for multiple comparison was run if the number of groups exceeded two (B, D)).

phipods using an abundant littoral species, E.cyaneus. In particular, we looked at the factors contributing to coloration and estimated the dietary influence on carbohydrate reserves.

According to our results, E. cyaneus of different color morphs can change their color over time, adopting a brighter blue color in laboratory conditions (Fig. 2B, C). Indeed, shades of blue were correlated to the total carotenoid content but not the content of the crustacyanin analog proteins (Fig. 3). This is in contrast to high levels of crustacyanin analog proteins in bright blue animals and low carotenoid levels in bright orange individuals (Drozdova et al., 2020). Carotenoid levels, as expected, were consistent across bright blue and orange animals (Fig. S2), suggesting that body color in E.cyaneus is a result of the interplay between carotenoid and crustacyanin analog protein levels, and carotenoids are the main factor for defining the shade of blue in this species.

As carotenoids come from food, color should depend on diet composition. To confirm this hypothesis, we fed amphipods diets containing different amounts of carotenoids (Fig. 1B). We found that over the approximately two-month period, diet did not significantly change total carotenoid content, but a BFM diet resulted in brighter red antennae than TC and DG diets (Fig. 4C, D). Antennae color may correlate to factors other than total carotenoid content, or the mechanism of color formation in antennae may be different from the rest of the body, since they are usually a different color than the main body color. Finally, we cannot rule out the possibility that the experimental duration, while sufficient to reveal the difference in antennae color, was insufficient to reveal a difference in body color.

Our data indicate that none of the three tested diets can fully sustain the characteristic color of amphipods. The carotenoid composition of BFM collected from their natural habitat should be the closest to the natural diet and be easily metabolized. However, neither BFM, TC, nor DG could fully preserve the color of E.cyaneus over long-term laboratory rearing. DG was 

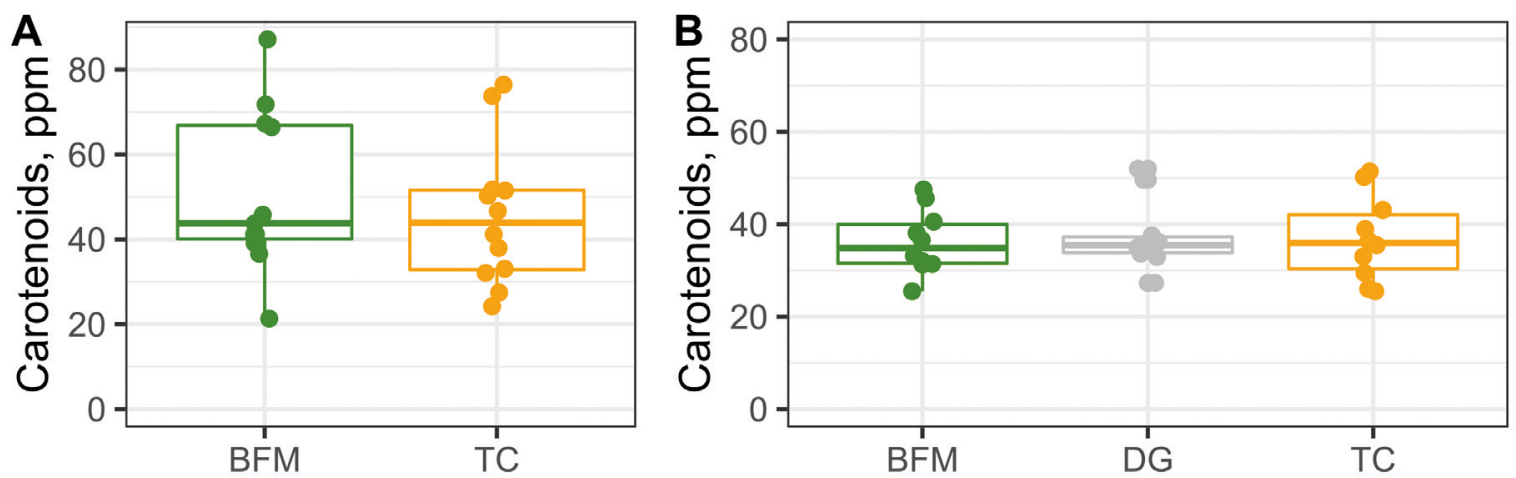

Feed

우 BFM

DG

TC
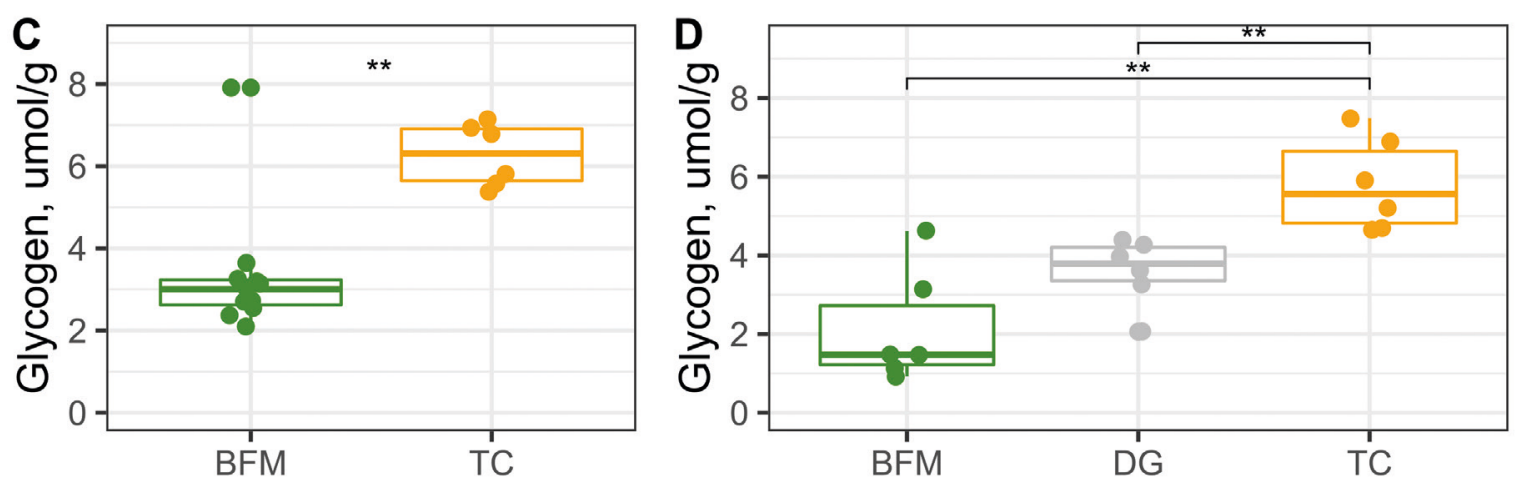

Feed

DG

TC
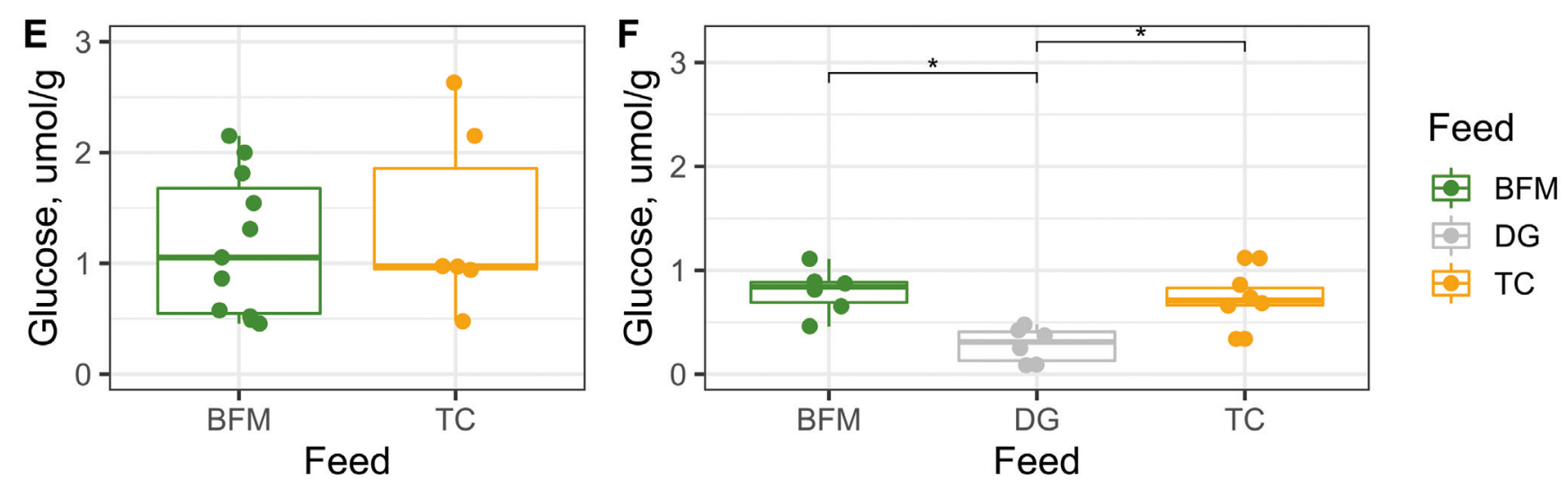

Fig. 5. Comparative analysis of carotenoid (A-B), glycogen (C-D), and glucose (E-F) content in different feeding groups. (A), (C), and (E) show the results of the first feeding experiment (summer cohort), while (B), (D), and (F) show the results of the second experiment (winter cohort). $* p<0.05 ;{ }^{* *} p<0.01$. For each group, $6-11$ pools with $2-4$ animals per pool were analyzed.

unable to maintain color, probably just due to the lack of carotenoids, and since TC is intended to feed decapods (shrimps and crabs), and the mechanism for color formation in amphipods is less understood, the diet composition, even though high in carotenoids, may have still been inadequate. Indeed, the proportion of astaxanthin and its derivatives in total carotenoids in Baikal gammarids is only between 13.31 and $51.27 \%$ (Czeczuga, 1975; Czeczuga, 1980; Dembitsky and Rezanka, 1996; Gaillard et al., 2004), and in decapods astaxanthin is dominant (67-95\%) (Tanaka et al., 1976; Jussila, 1997; CoralHinostroza and Bjerkeng, 2002; Su et al., 2018; Weaver, 2020). Along with our data (Fig. 5A, B), it is likely that carotenoids in decapod-oriented TC are not properly metabolized in amphipods due to the difference in prevailing carotenoids between decapods and amphipods.

We show that the type of diet influences the level of glycogen in E.cyaneus. Diet variation results in different levels of accumulated glycogen. Interestingly, glucose level did not correlate with glycogen level and was similar for both BFM and TC. The similar weights of animals from different diets and similar mortality levels in winter (Fig. S3 and S4) corroborate previous studies (AxenovGribanov et al., 2019) and also confirm that all studied diets are acceptable for this species. Overall, while additional research is required to determine the optimal 
diet composition for long-term rearing of E.cyaneus, additional supplementation is required if a BFM-based diet is used. However, our data (Fig. 5C, D) suggest that both TC- and DG-based diets support viability and even promote glycogen accumulation in the animals.

Taken together with previous studies (Timofeyev et al., 2009; Axenov-Gribanov et al., 2019), our data confirm that long-term laboratory rearing affects color formation, metabolism, the stress response, and other factors in amphipods. It remains unclear if the recorded changes in antioxidant enzyme activities (Timofeyev et al., 2009; Axenov-Gribanov et al., 2019) and color changes (this work) bear negative consequences for the overall state of the cultured animals. However, these data do highlight the importance of adjusting, documenting, and standardizing rearing procedures for each group of species to be laboratory reared.

\section{Acknowledgments}

We are grateful to the Institute of Biology for their field and laboratory assistance, especially to Ekaterina Madyarova and Yaroslav Rzhechitskiy for their help with animal sampling and Dr. Zhanna Shatilina and Dr. Anton Gurkov for critical reading of the manuscript.

\section{References}

Alberts-Hubatsch, H., Slater, M.J., and Beermann, J. 2019. Effect of diet on growth, survival and fatty acid profile of marine amphipods: implications for utilisation as a feed ingredient for sustainable aquaculture. Aquaculture Environment Interactions 11:481-491. https://doi. org/10.3354/aei00329

Alonso, Á., De Lange, H. J., and Peeters, E. T. 2010. Contrasting sensitivities to toxicants of the freshwater amphipods Gammarus pulex and G. fossarum. Ecotoxicology 19(1):133. https://doi.org/10.1007/s10646-009-0398-y

Arfianti, T., Wilson, S., and Costello, M.J. 2018. Progress in the discovery of amphipod crustaceans. Peerj 6:e5187. https://doi.org/10.7717/peerj.5187

Artal, M. C., Dos Santos, A., Henry, T. B., and de Aragão Umbuzeiro, G. 2018. Development of an acute toxicity test with the tropical marine amphipod Parhyale hawaiensis. Ecotoxicology 27(2):103-108. https://doi.org/10.1007/ s10646-017-1875-3

Axenov-Gribanov, D.V., Bedulina, D.S., Shirokova, Y.A., Emshanova, V.A., Lubyaga, Y.A., Vereshchagina, K.P., Saranchina, A.E., Pobezhimova, T.P., and Timofeyev, M. A. 2019. Diet influence on mechanisms of non-specific stress-response in Baikal endemic amphipod species during long-term laboratory exposure. Crustaceana 92(11-12):1349-1368. https://doi. org/10.1163/15685403-00003951

Babin, A., Motreuil, S., Teixeira, M., Bauer, A., Rigaud, T., Moreau, J., and Moret, Y. 2020. Origin of the natural variation in the storage of dietary carotenoids in freshwater amphipod crustaceans. PloS ONE 15(4):e0231247. https://doi.org/10.1371/journal.pone.0231247

Baeza-Rojano, E., García, S., Garrido, D., Guerra-García, J. M., and Domingues, P. 2010. Use of amphipods as alternative prey to culture cuttlefish (Sepia officinalis) hatchlings. Aquaculture 300(1-4):243-246. https://doi.org/10.1016/j. aquaculture.2009.12.029
Beatty, R.A. 1949. The pigmentation of cavernicolous animals: III. The Carotenoid pigments of some amphipod Crustacea. Journal of Experimental Biology 26(2):125-130. https://doi.org/10.1242/jeb.26.2.125

Bedulina, D. S., Evgen'ev, M. B., Timofeyev, M. A., Protopopova, M. V., Garbuz, D. G., Pavlichenko, V. V., Luckenbach, T., Shatilina, Z. M. , Axenov-Gribanov, D. V., Gurkov, A. N., Sokolova, I. M., and Zatsepina, O. G. 2013. Expression patterns and organization of the $h s p 70$ genes correlate with thermotolerance in two congener endemic amphipod species (Eulimnogammarus cyaneus and E.verrucosus) from Lake Baikal. Molecular Ecology 22(5):14161430. https://doi.org/10.1111/mec.12136

Bedulina, D. S., Takhteev, V. V., Pogrebnyak, S. G., Govorukhina, E. B., Madyarova, E. V., and Lubyaga, Y. A. 2014. On Eulimnogammarus messerschmidtii, sp. n. (Amphipoda: Gammaridea). Zootaxa 3838(5):518-544. https://doi. org/10.11646/zootaxa.3838.5.2

Bedulina, D., Drozdova, P., Gurkov, A., von Bergen, M., Stadler, P. F., Luckenbach, T., Timofeyev, M. A., and Kalkhof, S. 2020. Proteomics reveals sex-specific heat shock response of Baikal amphipod Eulimnogammarus cyaneus. Science of The Total Environment 763:143008. https:// doi.org/10.1016/j.scitotenv.2020.143008

Belykh, O. I., Ekaterina, G., Sorokovikova, T., Saphonova, A., and Tikhonova, I. V. 2006. Autotrophic picoplankton of Lake Baikal: composition, abundance and structure. Hydrobiologia 568(1):9-17. https://doi.org/10.1007/s10750006-0340-8

Brix, S., Lorz, A. N., Jazdzewska, A. M., Hughes, L., Tandberg, A.H.S., Pabis, K., Stransky, B., Krapp-Schickel, T., and Sorbe, J. C. 2018. Amphipod family distributions around Iceland. ZooKeys 731:1-53. https://doi. org/10.3897/zookeys.731.19854

Chayen, N. E., Cianci, M., Grossmann, J. G., Habash, J., Helliwell, J. R., Nneji, G. A., Raftery, J., Pierre, J. R., and Zagalsky, P.F. 2003. Unravelling the structural chemistry of the colouration mechanism in lobster shell. Acta Crystallographica. Section D, Biological Crystallography 59(12):2072-2082. https://doi.org/10.1107/ s0907444903025952

Coral-Hinostroza, G. N. and Bjerkeng, B. 2002. Astaxanthin from the red crab langostilla (Pleuroncodes planipes): optical R/S isomers and fatty acid moieties of astaxanthin esters. Comparative Biochemistry and Physiology Part B: Biochemistry and Molecular Biology 133(3):437-444. https://doi.org/10.1016/S1096-4959(02)00186-0

Czeczuga, B. 1975. Carotenoids in thirteen species of gammaridae from Lake Bajkał. Comparative Biochemistry and Physiology Part B: Biochemistry and Molecular Biology 50(2):259-268. https://doi.org/10.1016/03050491(75)90272-2

Czeczuga, B. 1980. Changes occurring during the annual cycle in the carotenoid content of Gammarus lacustris GO Sars (Crustacea: Amphipoda) specimens from the river $\mathrm{Na}$ rew. Comparative Biochemistry and Physiology Part B: Biochemistry and Molecular Biology 66(4):569-572. https:// doi.org/10.1016/0305-0491(80)90250-3

Dembitsky, V. M. and Rezanka, T. 1996. Comparative study of the endemic freshwater fauna of Lake Baikal-VII. Carotenoid composition of the deep-water amphipod crustacean Acanthogammarus (Brachyuropus) grewingkii. Comparative Biochemistry and Physiology Part B: Biochemistry and Molecular Biology 114(4):383-387. https://doi. org/10.1016/0305-0491(96)00066-1

Drozdova, P., Saranchina, A., Morgunova, M., Kizenko, A., Lubyaga, Y., Baduev, B., and Timofeyev, M. 2020. The level of putative carotenoid-binding proteins determines 
the body color in two species of endemic Lake Baikal amphipods. PeerJ 8:e9387. https://doi.org/10.7717/ peerj.9387

Du, J., Xu, S., Zhou, Q., Li, H., Fu, L., Tang, J., Wang, Y., Peng, X., $X u, Y .$, and $D u, X .2020$. A review of microplastics in the aquatic environmental: distribution, transport, ecotoxicology, and toxicological mechanisms. Environmental Science and Pollution Research 27:11494-11505. https://doi. org/10.1007/s11356-020-08104-9

Dybowsky, B. N. 1874. Beiträge zur näheren Kenntniss der in dem Baikal-See vorkommenden niederen Krebse aus der Gruppe der Gammariden (Vol. 10), St. Petersburg, Buchdrukerei. von W. Besobrasoff \& Comp. https://doi. org/10.5962/bhl.title.9945

Fietz, S., Bleiß, W., Hepperle, D., Koppitz, H., Krienitz, L., and Nicklisch, A. 2005. First record of Nannochloropsis limnetica (Eustigmatophyceae) in the autotrophic picoplankton from Lake Baikal. Journal of Phycology 41(4):780-790. https://doi.org/10.1111/j.0022-3646.2005.04198.x

Fišer, C., Konec, M., Alther, R., Švara, V., and Altermatt, F. 2017. Taxonomic, phylogenetic and ecological diversity of Niphargus (Amphipoda: Crustacea) in the Hölloch cave system (Switzerland). Systematics and Biodiversity 15(3):218-237. https://doi.org/10.1080/14772000.2016. 1249112

Gaillard, M., Juillet, C., Cézilly, F., and Perrot-Minnot, M.J. 2004. Carotenoids of two freshwater amphipod species (Gammarus pulex and G. roeseli) and their common acanthocephalan parasite Polymorphus minutus. Comparative Biochemistry and Physiology Part B: Biochemistry and Molecular Biology 139(1):129-136. https://doi.org/10.1016/j. cbpc.2004.07.001

Gurkov, A., Rivarola-Duarte, L., Bedulina, D., Casas, I. F., Michael, H., Drozdova, P., Nazarova, A., Govorukhina, E., Timofeyev, M., Stadler, P. F., and Luckenbach, T. 2019. Indication of ongoing amphipod speciation in Lake Baikal by genetic structures within endemic species. BMC Evolutionary Biology 19:138. https://doi.org/10.1186/ s12862-019-1470-8

Hervant, F., Mathieu, J., and Barré, H. 1999. Comparative study on the metabolic responses of subterranean and surface-dwelling amphipods to long-term starvation and subsequent refeeding. Journal of Experimental Biology 202(24):3587-3595. https://doi.org/10.1242/ jeb.202.24.3587

Hyne, R. V., Gale, S. A., and King, C. K. 2005. Laboratory culture and life-cycle experiments with the benthic amphipod Melita plumulosa (Zeidler). Environmental Toxicology and Chemistry 24(8):2065-2073. https://doi.org/10.1897/04409R1.1

Jakob, L., Bedulina, D.S., Axenov-Gribanov, D. V., Ginzburg, M., Shatilina, Z. M., Lubyaga, Y. A., Madyarova, E. V., Gurkov, A. N., Timofeyev, M. A., Pörtner, H.-O., Sartoris, F. J., Altenburger, R., and Luckenbach, T. 2017. Uptake kinetics and subcellular compartmentalization explain lethal but not sublethal effects of cadmium in two closely related amphipod species. Environmental Science \& Technology 51(12):7208-7218. https://doi.org/10.1021/ acs.est.6b06613

Jussila, J. 1997. Physiological responses of astacid and parastacid crayfishes (Crustacea: Decapoda) to conditions of intensive culture. Western Australia: University of Kuopio, $140 \mathrm{p}$.

Lubyaga, Y., Trifonova, M., Drozdova, P., Gurkov, A., Madyarova, E., Axenov-Gribanov, D., Kurashov, E, Vereshchagina, K., Shatilina, Z., and Timofeyev, M. 2020. Invader amphipods Gmelinoides fasciatus (Stebbing, 1899) inhabiting distant waterbodies demonstrate differences in tolerance and energy metabolism under elevated temperatures. Journal of Great Lakes Research 46(4):899-909. https://doi.org/10.1016/j.jglr.2020.05.011

Macdonald III, K.S., Yampolsky, L., and Duffy, J.E. 2005. Molecular and morphological evolution of the amphipod radiation of Lake Baikal. Molecular Phylogenetics and Evolution 35(2):323-343. https://doi.org/10.1016/j. ympev.2005.01.013

Maoka, T. 2011. Carotenoids in marine animals. Marine Drugs 9(2):278-293. https://doi.org/10.3390/md9020278

Maoka, T. 2020. Carotenoids as natural functional pigments. Journal of Natural Medicines 74:1-16. https://doi. org/10.1007/s11418-019-01364-x

McCahon, C. P. and Pascoe, D. 1988. Culture techniques for three freshwater macroinvertebrate species and their use in toxicity tests. Chemosphere 17(12):2471-2480. https://doi.org/10.1016/0045-6535(88)90157-9

Mekhanikova, I. V. 2015. Morphology of mouthpart and feeding of Eulimnogammarus cyaneus (Crustacea, Amphipoda), an inhabitant of the Lake Baikal nearshore zone. Zoologicheskii Zhurnal 94(12):1379-1386. https://doi. org/10.7868/S0044513415120107 (In Russian)

Morino, H., Kamaltynov, R. M., Nakai, K., and Mashiko, K. 2000. Phenetic analysis, trophic specialization and habitat partitioning in the Baikal amphipod genus Eulimnogammarus (Crustacea). Advances in Ecological Research 31:355376. https://doi.org/10.1016/S0065-2504(00)31019-4

Naumenko, S. A., Logacheva, M.D., Popova, N. V., Klepikova, A. V., Penin, A.A., Bazykin, G.A., Etingova, A. E., Mugue, N.S., Kondrashov, A.S., and Yampolsky, L. Y. 2017. Transcriptome-based phylogeny of endemic Lake Baikal amphipod species flock: fast speciation accompanied by frequent episodes of positive selection. Molecular Ecology 26(2):536-553. https://doi.org/10.1111/ mec.13927

Pascoe, D. and Othman, M. S. 2001. Growth, development and reproduction of Hyalella azteca (Saussure, 1858) in laboratory culture. Crustaceana 74(2):171-181. https:// doi.org/10.1163/156854001750096274

Podlesińska, W. and Dąbrowska, H. 2019. Amphipods in estuarine and marine quality assessment - a review. Oceanologia 61(2):179-196. https://doi.org/10.1016/j. oceano.2018.09.002

R Core Team. 2019. A language and environment for statistical computing. R foundation for statistical computing. Vienna, Austria. https://www.r-project.org

Schindelin, J., Arganda-Carreras, I., Frise, E., Kaynig, V., Longair, M., Pietzsch, T., Preibisch, S., Rueden, C., Saalfeld, S., Schmid, B., Tinevez, J.-Y., White, D.J., Hartenstein, V., Eliceiri, K., Tomancak, P., and Cardona, A. 2012. Fiji: an open-source platform for biological-image analysis. Nature Methods 9(7):676-682. https://doi.org/10.1038/ nmeth.2019

Schneider, C. A., Rasband, W. S., and Eliceiri, K. W. 2012. NIH Image to Image): 25 years of image. Nature Methods 9(7):671-675. https://doi.org/10.1038/nmeth.2089

Semsar-Kazerouni, M., Boerrigter, J. G., and Verberk, W. C. 2020. Changes in heat stress tolerance in a freshwater amphipod following starvation: The role of oxygen availability, metabolic rate, heat shock proteins and energy reserves. Comparative Biochemistry and Physiology Part A: Molecular \& Integrative Physiology 245:110697. https:// doi.org/10.1016/j.cbpa.2020.110697

Spicer, J. I., Moore, P. G., and Taylor, A. C. 1987. The physiological ecology of land invasion by the Talitridae (Crustacea: Amphipoda). Proceedings of the Royal Society of London. Series B. Biological Sciences 232(1266):95-124. https:// doi.org/10.1098/rspb.1987.0063 
Su, F., Huang, B., and Liu, J. 2018. The carotenoids of shrimps (Decapoda: Caridea and Dendrobranchiata) cultured in China. Journal of Crustacean Biology 38(5):523-530. https://doi.org/10.1093/jcbiol/ruy049

Takhteev, V. V. 2019. On the current state of taxonomy of the Baikal Lake amphipods (Crustacea: Amphipoda) and the typological ways of constructing their system. Arthropoda Selecta 28(3):374-402. https://doi.org/10.15298/arthsel.28.3.03

Tanaka, Y., Matsuguchi, H., Katayama, T., Simpson, K. L., and Chichester, C. O. 1976. The biosynthesis of astaxanthin - XVI. The carotenoids in crustacea. Comparative Biochemistry and Physiology Part B: Biochemistry and Molecular Biology 54(3):391-393. https://doi. org/10.1016/0305-0491(76)90263-7

Thoen, H. H., Johnsen, G., and Berge, J. 2011. Pigmentation and spectral absorbance in the deep-sea arctic amphipods Eurythenes gryllus and Anonyx sp. Polar Biology 34(1):83-93. https://doi.org/10.1007/s00300-010-0861-5

Timofeyev, M. A., Protopopova, M., Pavlichenko, V., and Steinberg, C. E. 2009. Can acclimation of amphipods change their antioxidative response? Aquatic Ecology 43(4):1041. https://doi.org/10.1007/s10452-008-9217-4

Kamaltynov, R. M. 2001. Amphipods (Amphipoda, Gammaroidea); pp. 573-831 in: Timoshkin, O. A. (Ed.), Lake Baikal: diversity of fauna, problems of its immiscibility and origin, ecology and "exotic" communities. Index of animal species inhabiting Lake Baikal and its catchment area, Nauka, Novosibirsk. (In Russian)

Tlusty, M. and Hyland, C. 2005. Astaxanthin deposition in the cuticle of juvenile American lobster (Homarus americanus): implications for phenotypic and genotypic coloration. Marine Biology 147(1):113-119. https://doi. org/10.1007/s00227-005-1558-0

Vargas-Abúndez, J. A., López-Vázquez, H. I., Mascaró, M., Martínez-Moreno, G. L., and Simões, N. 2021. Marine amphipods as a new live prey for ornamental aquaculture: exploring the potential of Parhyale hawaiensis and Elasmopus pectenicrus. PeerJ 9:10840. https://doi.org/10.7717/ peerj.10840

Vereshchagina, K. P., Lubyaga, Y. A., Shatilina, Z., Bedulina, D., Gurkov, A., Axenov-Gribanov, D. V., Baduev, B. , Kondrateva, E. S., Gubanov, M. Zadereev, E., Sokolova, I. and Timofeyev, M. 2016. Salinity modulates thermotolerance, energy metabolism and stress response in amphipods Gammarus lacustris. PeerJ 4:e2657. https://doi. org/10.7717/peerj.2657
Villacorta, C., Jaume, D., Oromí, P., and Juan, C. 2008. Under the volcano: phylogeography and evolution of the cavedwelling Palmorchestia hypogaea (Amphipoda, Crustacea) at La Palma (Canary Islands). BMC Biology 6(1):1-14. https://doi.org/10.1186/1741-7007-6-7

Väinölä, R., Witt, J.D. S., Grabowski, M., Bradbury, J. H., Jazdzewski, K., and Sket, B. 2008. Global diversity of amphipods (Amphipoda; Crustacea) in freshwater. Hydrobiologia 595:241-255. https://doi.org/10.1007/s10750007-9020-6

Wade, N. M., Gabaudan, J., and Glencross, B. D. 2017. A review of carotenoid utilisation and function in crustacean aquaculture. Reviews in Aquaculture 9(2):141-156. https://doi.org/10.1111/raq.12109

Wang, W., Ishikawa, M., Koshio, S., Yokoyama, S., Hossain, M. S., and Moss, A. S. 2018. Effects of dietary astaxanthin supplementation on juvenile kuruma shrimp, Marsupenaeus japonicus. Aquaculture 491:197-204. https://doi.org/10.1016/j.aquaculture.2018.03.025

Wattier, R., Mamos, T., Copilaş-Ciocianu, D., Jelić, M., Ollivier, A., Chaumot, A., Danger, M., Felten, V., Piscart, C., Žganec, K., and Rewicz, T. 2020. Continental-scale patterns of hyper-cryptic diversity within the freshwater model taxon Gammarus fossarum (Crustacea, Amphipoda). Scientific Reports 10(1):16536. https://doi. org/10.1038/s41598-020-73739-0

Weaver, R. J., Gonzalez, B. K., Santos, S. R., and Havird, J. C. 2020. Red coloration in an anchialine shrimp: carotenoids, genetic variation, and candidate genes. The Biological Bulletin 238(2):119-130. https://doi. org/10.1086/708625

Wickham, H. 2016. ggplot2: elegant graphics for data analysis. Springer. https://doi.org/10.1007/978-3-319-24277-4

Wildish, D. J., Pavesi, L., and Ketmaier, V. 2012. Talitrid amphipods (Crustacea: Amphipoda: Talitridae) and the driftwood ecological niche: a morphological and molecular study. Journal of Natural History 46(43-44):2677-2700. https://doi.org/10.1080/00222933.2012.717971

Woods, C.M. 2009. Caprellid amphipods: an overlooked marine finfish aquaculture resource? Aquaculture 289(3-4):199-211. https://doi.org/10.1016/j.aquaculture.2009.01.018

Xavier, J. C., Cherel, Y., Boxshall, G., Brandt, A., Coffer, T., Forman, J., Havermans, C., Jażdżewska, A., Kouwenberg, J., Schnabel, K., and Schiaparelli, S. 2020. Crustacean guide for predator studies in the Southern Ocean. Scientific Committee on Antarctic Research, 253 p. 